\title{
Fragmentos de La Memoria Colectiva
}

\author{
Maurice Halbwachs
}

\section{Selección y traducción: Miguel Angel Aguilar D. Universidad Autónoma Metropolitana -Iztapalapa Licenciatura en Psicología Social}

(Publicado originalmente en Revista de Cultura Psicológica, Año 1, Número 1, México, UNAMFacultad de psicología, 1991).

\section{Resumen}

La memoria es un hecho y un proceso colectivo. La existencia de un lenguaje y significación común a los miembros de un grupo hacen que estos vuelvan a su pasado de manera colectiva, es decir dotando de un sentido compartido a los eventos que los han constituido como una entidad. La memoria histórica es una y se cierra sobre los limites que un proceso de decantación social le ha impuesto; la memoria colectiva es múltiple y se transforma a medida que es actualizada por los grupos que participan de ella: el pasado nunca es el mismo.

Palabras clave: Memoria, memoria colectiva, Temporalidad.

\section{Abstract}

The making of the memory is a collective process. The presence of a common language and significance in the members of a group makes them to turn to their past in a collective way; in other words, they invest with the same and shared sense the events that constituted them as an entity.

The historic memory is one and close itself upon the limits that a process of social decantation imposes; collective memory is diverse and is transformed when is actualized by the groups that participate in its reconstrution: the pas never is the same.

Keywords: Memory, Collective Memory Temporal.

\section{PRESENTACIÓN}

El texto de La Memoria Colectiva aparece publicado en 1950 como obra póstuma. Su redacción data de 1941- 1944, y es en realidad una compilación de notas y ensayos que Maurice Halbwachs escribiera hasta antes de su deportación y muerte en el campo de concentración de Buchenwald en 1945. 
Las ideas centrales del libro desarrollan y van más allá de los planteamientos realizados por el autor en Loscuadros sociales de la memoria ( París, Alcan, 1924) y la topografía legendaria de los evangelios en tierra santa (París, P.U.F., 1941). Aparece, como constante en los libros dedicados por Halbwachs al tema de la memoria, la necesidad de argumentar la naturaleza social de los procesos que permiten reconocerse como tales a grupos e individuos. Así, la búsqueda de la memoria (perdida o recuperada ) deviene en le fondo la búsqueda de las estrategias que permiten a una sociedad o aun grupo tener conocimiento de sí mismo, de manera que se logre una solución de continuidad e identidad frente al tiempo y al pasado.

Lo que en un principio fueron fichas personales de trabajo han sido ordenadas y revisadas para permitir su uso en la docencia e investigación en un momento en el que el tema resulta de interés y no existen en nuestro idioma algunos de los trabajos pioneros al respecto. Dada la presentación fragmentaria del texto, cabe señalar que se ha procurado traducir la argumentación central respecto a memoria individual y la memoria colectiva (capítulo 1); memoria colectiva y memoria histórica (capítulo 2); la memoria colectiva y el espacio (capítulo 4). Lamentablemente no se reproducen los amplios e interesantes ejemplos que da el autor para ilustrar su tesis. A manera de compensación se buscó respetar al máximo es estilo del autor; un estilo hecho de largas frases, cláusulas subordinadas, dobles negaciones y una cierta intención literaria que lo convierte en una lectura atractiva.

\section{NOTA DEL COMITÉ EDITORIAL SOBRE EL CONCEPTO DE MEMORIA COLECTIVA DE MAURICE HALBWACHS.}

El concepto de Memoria Colectiva es original del sociólogo francés Maurice Halbwchs, de vida muy productiva y muerte muy absurda. Entre la docena de libros que escribió, cuyos temas van desde el cálculo de probabilidades hasta la morfología social, tres se refieren al de la memoria colectiva: el primero escrito en 1925, sobre los marcos sociales de la memoria, el segundo en 1941, que versa sobre una investigación sobre la memoria de los lugares evangélicos en Tierra Santa, y el tercero, publicado póstumamente en 1950, que se intitula ya simplemente La Memoria Colectiva. Ninguno ha sido traducido aún en español. En todo caso, según Halbwachs, la memoria colectiva es el proceso social de reconstrucción del pasado vivido y experimentado por un determinado grupo, comunidad o sociedad. Este pasado vivido es distinto a la historia, la cual se refiere más bien ala serie de fechas y eventos registrados, como datos y como hechos, independientemente de si éstos han sido sentidos y experimentados por alguien. Mientras que la historia pretende dar cuenta de las transformaciones de la sociedad, la memoria colectiva insiste en asegurar la permanencia del tiempo y la homogeneidad de la vida, como en un intento por mostrar que el pasado permanece, que nada ha cambiado dentro del grupo y, por ende, junto con el pasado, la identidad de ese grupo también permanece, así como sus proyectos. Mientras que la historia es informativa, la memoria es comunicativa, por lo que los datos verídicos no le interesan, sino que le interesan las experiencias verídicas por medio de las cuales se permite transtocar e inventar el pasado cuanto haga menester. Los grupos tienen necesidad de reconstruir permanentemente sus recuerdos a través de sus conversaciones, contactos, rememoraciones, efemérides, usos y costumbres, conservación de sus objetos y pertenencias y permanencia en los lugares en donde se ha desarrollado su vida, porque la memoria es la única garantía de que el grupo sigue siendo el mismo, en medio de un mundo en perpetuo movimiento. Toda memoria, incluso la individual, se gesta y se apoya en el pensamiento y la comunicación del 
grupo: cada uno está seguro de sus recuerdos porque los demás también los conocen, aunque el evento recordado no haya existido realmente, como en el caso de las anécdotas de la infancia, que uno tiene que llegar a creerlas, en incluso a recordarlas, o hasta ir a contárselas al psicoanalista, porque el resto de la familia asegura que son ciertas.

Ahora bien, la comunicación y el pensamiento de los diversos grupos de la sociedad está estructurado en marcos, los marcos sociales de la memoria. De los distintos posibles, los básicos son los marcos temporales y los marcos espaciales. Los marcos temporales de la memoria colectiva están armados con todas las fechas de festividades, nacimientos, defunciones, aniversarios, cambios de estación, etcétera, que funcionan como puntos de referencia, como hitos a los cuales hay que recurrir para encontrar los recuerdos: las fechas y períodos que son considerados socialmente significativos siempre tienen un recuerdo construido, y así, con base en estos mojones, se puede ir configurando una biografía congruente de individuos y grupos: ante la aparición de una fecha importante, de un aniversario individual, cívico o religioso. El pensamiento va aparecer ante sí los recuerdos que de otra manera no existirían porque no hubieran sido recordados; en efecto, los recuerdos están más en los marcos, en los hitos, en las fechas, que en los pensamientos, como cuando uno se acuerda de una obligación porque se entera de que hoy es viernes. En el tiempo está depositada la memoria, como si la memoria fuera un objeto y el tiempo fuera un lugar, y si faltan estos lugares, el recuerdo que contenían no puede ser devuelto, como cuando uno se olvida de una obligación porque no se enteró de que hoy era viernes. Y es que el tiempo es igual al espacio, solamente que hecho de minutos en vez de centímetros. Así los marcos espaciales de la memoria colectiva consisten en los lugares, las construcciones y los objetos, donde, por vivir en y con ellos, se ha ido depositando la memoria de los grupos, de modo que tal esquina, tal bar, tal objeto, en fin, evocan el recuerdo de la vida social que fue vivida ahí y su ausencia, pérdida o destrucción impide la reconstrucción de la memoria; con cada edificio que se derrumba, un trocito de pensamiento colectivo se rompe, queda inconcluso. El espacio es fundamental a la memoria colectiva, porque al revés del tiempo, que está hecho de convenciones, éste está hecho de piedra inerte, que es más estable y durable, y puede mantener así la memoria viva por más tiempo: la permanencia de una edificación significa para los interesados la permanencia de sus recuerdos, porque en efecto, como se dice cotidianamente, "las cosas traen recuerdos", frase que debe entenderse literalmente. Pero, no obstante, la importancia del espacio se vuelve doble para la memoria por el hecho de que aun que una construcción se destruya, siempre podrá decirse que "aquí estuvo", porque en efecto, la traza, el emplazamiento, es lo último que se borra. Por eso Halbwachs dedicó una investigación minuciosa a los espacios de la memoria, y, por eso mismo, cuando define a la memoria colectiva, la encuentra sobre todo depositada en el espacio: "no es exacto que para poder recordar haya que transportarse con el pensamiento afuera del espacio, puesto que, por el contrario, es la sola imagen del espacio la que, en razón de su estabilidad, nos da la ilusión de no cambiar a través del tiempo, y de encontrar el pasado dentro del presente, que es precisamente la forma en que puede definirse a la memoria; sólo el espacio es tan estable que puede durar sin envejecer ni perder alguna de sus partes" (1950,p. 167). 


\section{Capítulo Primero}

\section{Memoria Individual y Memoria Colectiva}

1.p.2. Los recuerdos son colectivos y nos son traídos a la conciencia por otras personas, aun cuando se trate de hechos que nos han ocurrido sólo a nosotros y de objetos que únicamente nosotros hemos visto. $Y$ es que en realidad nunca estamos solos. No hace falta que otros hombres estén presentes, que se distingan materialmente de nosotros: siempre llevamos en nosotros y con nosotros un cierto número de personas inconfundibles.

2.p.3. así, para confirmar o recordar un evento ocurrido en el pasado, no son necesarios los individuos presentes bajo una forma sensible y material. En efecto, ocurre que una o más personas reuniendo sus recuerdos puedas describir exactamente hechos $u$ objetos que nosotros hemos visto al mismo tiempo que ellos, e incluso reconstruir todos nuestros actos y nuestras palabras en circunstancias definidas, sin que necesariamente nos recordemos de ello.

3.p.5. Cuando decimos que un testimonio no nos diría nada si no ha quedado en nuestro espíritu alguna imagen del evento pasado que se intenta evocar, no queremos decir que el recuerdo ha debido de subsistir tal cual en nosotros, sino solamente que a partir del mo0mento en que nosotros y los testimoniantes formamos parte de un mismo grupo y pensamos en común bajo ciertas relaciones hemos permanecido en contacto con este grupo y somos capaces de identificarnos con él confundir nuestro pasado con el suyo. Podría decirse igualmente que: es necesario que después de ese momento no hayamos perdido de ninguna forma la costumbre ni la posibilidad de pensar y recordar en tanto que miembros de grupo de cuyo testimonio nosotros mismos formamos parte, es decir ubicándonos en su punto de vista empleando todas las nociones que son comunes a sus miembros.

4.p.12. ¿es posible que la memoria individual en tanto que se opone a la memoria colectiva, sea una condición necesaria y suficiente de la evocación y reconocimiento de recuerdos? De ninguna manera. Porque si se pierde un primer recuerdo, si no es posible ya encontrarlo, es que hace mucho tiempo que no formamos parte del grupo en cuya memoria se conserva. Para que nuestra memoria se ayude de la de otros no es suficiente que éstos nos proporciones sus testimonios: hace falta que no hayan cesado de relacionarse con sus recuerdos y que tengan bastantes puntos de contacto entre unos y otros para que el recuerdo evocado pueda ser construido bajo un fundamento común. Es insuficiente reconstruir pieza por pieza la imagen de un suceso pasado para obtener un recuerdo. Hace falta que esta reconstrucción (del pasado) opere a partir de datos o de nociones comunes que se encuentran en nuestro espíritu lo mismo que en el de los otros, para que estos pasen sin cesar de estos a aquellos recíprocamente, lo que es posible sólo si han formado parte y continúan formando parte de una misma sociedad. Solamente así se puede comprender que un recuerdo puede ser ala vez reconocido y reconstruido.

5.p.15. Posiblemente se nos conceda que un gran número de recuerdos reaparecen dado que otras personas los evocan en nosotros: también se concederá que cuando estos hombres no se encuentran presentes se puede hablar de memoria colectiva, dado que evocamos un evento que ocurre en la vida de nuestro grupo, y que lo valoramos desde el punto de vista de este grupo.

6.p.16. ¿Existen recuerdos que reaparecen sin que de ninguna forma sea posible ponerlos en relación con un grupo, ya que el evento que reproducen ha sido percibido por nosotros cuando estábamos solos, no en apariencia, sino realmente solos, cuya imagen no se ubica en el pensamiento 
de un conjunto de hombres, y que nosotros recordemos al colocarnos en un punto de vista que es estrictamente nuestro? A pesar de este tipo de fenómenos sean raros, e incluso excepcionales, bastaría que pudiéramos atestiguar algunos de ellos para establecer que la memoria colectiva no explica todos nuestros recuerdos, y posiblemente, no explique por sí misma la evocación de no importa qué recuerdo.

7.p.26. Del primer nivel de la memoria colectiva de un grupo se desprenden los recuerdos de hechos y de experiencias que conciernen a la mayor parte de sus miembros y que resultan, sea de su vida propia o sea de relaciones con los grupos más próximos con los que tienen un mayor contacto. Por lo que toca a aquellos recuerdos que conciernen a un número restringido de los miembros del grupo, aun cuando estén ubicados en su memoria, pasan a un segundo plano general.

8.p.27. De ordinario un grupo entra en relación con otros grupos. Una gran cantidad de sucesos resultan de estos contactos, lo mismo que diversas nociones que encuentran en el grupo su origen único. En ocasiones estas relaciones o contactos son permanentes o bien se repiten con frecuencia con una duración bastante amplia. Por ejemplo, cuando una familia vive mucho tiempo en una misma ciudad, o en la cercanía de los mismos amigos, ciudad y familia, amigos y familia se constituyen como sociedades complejas. Es así como nacen recuerdos, comprendidos en marcos de pensamiento que son comunes a los miembros de estos dos grupos.

\section{El recuerdo individual como límite de interferencias colectivas.}

9.p.29.En la medida en que cedemos sin resistencia a una sugestión del exterior creemos que pensamos y actuamos libremente. Es así como la mayor parte de las influencias sociales a las que nos vemos sujetos nos pasan desapercibidas. Sin embargo, estas influencias se presentan igualmente, e incluso de manera más comprensible, cuando en el punto de encuentro de múltiples corrientes de pensamiento colectivo que se entrecruzan en nosotros se producen estados complejos, ahí donde se ha creído ver un suceso único que sólo existiera para nosotros.

10.p30. Estos recuerdos que nos parecen puramente personales, tal como los conocemos y somos capaces de reencontrarlos, se distinguen de otros por la complejidad de las condiciones necesarias para que sean evocados; se trata de una diferencia de grado.

11.p.31. Entre los recuerdos que evocamos a voluntad y aquellos sobre los cuales pareciera que no tenemos control encontraremos sólo diferencias de grado de complejidad para evocarlos. Los recuerdos evocables a voluntad se encuentran siempre a nuestro alcance, dado que se encuentran en los grados a los que podemos entrar sin dificultades, es pensamientos colectivos con los que permanecemos en un estrecho contacto, de tal modo que todos sus elementos, todos los vínculos entre estos elementos y los pasajes entre los unos y los otros nos son familiares. Los recuerdos sobre los que no tenemos control son menos y más difícilmente accesibles dado que los grupos que nos los brindarían se encuentran más alejados y sólo estamos en contacto con ellos de manera intermitente.

12.p.32. Veremos que estos fragmentos o elementos de los recuerdos personales, que parecerían pertenecer sólo a nosotros, pueden encontrarse y conservarse en ambientes sociales definidos y los miembros de estos grupos(de los cuales no dejamos de formar parte) podrían descubrirlos y mostrarlos si los interrogáramos de una manera adecuada.

13.p.33. Por lo demás, si la memoria colectiva obtienen su fuerza y su duración al tener por soporte a un conjunto de hombres, son, sin embargo, los individuos en tanto que miembros de un grupo los que 
recuerdan. De este conglomerado de recuerdos comunes que se apoyan unos sobre otros, no son los mismos los que aparecerán con igual intensidad para cada uno de los miembros de un grupo. Diremos, de buen grado, que cada memoria individual es un punto de vista sobre la memoria colectiva, este punto de vista se transforma de acuerdo con el lugar que ocupo, y que este mismo lugar cambia de acuerdo con las relaciones que establezco con otros medios sociales. Por tanto, no es de asombrar que de un instrumento común no todos obtengan el mismo beneficio. Sin embargo, cuando intenta explicar esta diversidad se desemboca siempre en una combinación de influencias, todas ellas de carácter social.

14.p.33. La sucesión de recuerdos, incluso aquellos más personales, se explica siempre por los cambios que se producen en nuestras relaciones con los diversos medios o ambientes colectivos, es decir, por las transformaciones de estos medios, cada uno de ellos tomado por separado y en conjunto.

15.p.34. En tanto que el recuerdo reaparece por el efecto de múltiples series de pensamientos colectivos interrelacionados y que no es posible atribuir esto exclusivamente a alguno de ellos nos figuramos que es independiente, y oponemos su unidad a multiplicidad. Esto es tanto como suponer que un objeto pesado, suspendido en el aire por una cierta cantidad de hilos tendidos y entrecruzados permanece sus pendido en el vacío, sosteniéndose por si mismo.

\section{Capítulo Segundo}

\section{Memoria Colectiva y Memoria Histórica}

16.p.34 Aún no se esta acostumbrado a hablar de la memoria de un grupo, ni siquiera metafóricamente. Tal parece que una facultad semejante no pudiera existir y durar más que si se encuentra ligada a un cuerpo o cerebro individual. Admitamos, sin embargo, que existen dos formas en que se organizan los recuerdos: agrupándose alrededor de una persona definida, quien los contempla de una manera determinada; o bien, distribuidos al interior de una sociedad, sea grande o pequeña, de la que son imágenes parciales. Existirán entonces memorias individuales y, si se quiere, memorias colectivas. Dicho de otra forma, el individuo participa en dos formas de memoria.

17.p.34. la memoria colectiva, por otra parte, agrupa a las memorias individuales, pero no se confunde con ellas. Esta (la memoria colectiva) evoluciona siguiendo sus leyes, y si ciertos recuerdos individuales penetran también algunas veces en ella, estos cambian de figura a partir de que son emplazados en un conjunto que no es ya una conciencia personal.

18.p.36. La memoria individual no se encuentra completamente cerrada y aislada. Un hombre para evocar su pasado tienen necesidad de apelar a los recuerdos de otros, se pone en relación con puntos de referencia que existen fuera de él y que son fijados por la sociedad. Aún más, el funcionamiento de la memoria individual no es posible sin los instrumentos que son las palabras y las ideas, que el individuo no ha inventado, y que son tomadas de su medio. No es menos verdadero que uno recuerde aquello que ha visto, sentido, pasado en un momento en el tiempo, es decir, que nuestra memoria no se confunde con la de otros. Ella se encuentra estrechamente limitada en el espacio y el tiempo. La memoria colectiva lo está también: pero los límites no son los mismos. 
19.p.37. Hay que distinguir entonces dos memorias que llamaremos, si se quiere, memoria interior o interna, y la otra exterior; o bien una memoria personal y una memoria social. Diremos más exactamente: memoria autobiográfica y memoria histórica. La primera se auxilia de la segunda dado que después de todo la historia de nuestra vida forma parte de la historia en general. Sin embargo, la segunda sería naturalmente de una extensión más amplia que la primera. Por otro lado, la memoria histórica nos presenta el pasado bajo una forma resumida y esquemática, mientras que la memoria de nuestra vida aparece en un contexto más continuo y denso.

20.p.39. Posiblemente a más de un psicólogo le gustaría plantear que, como auxiliares de nuestra memoria, los eventos históricos no desempeñan más que el papel de divisiones marcadas por un calendario, o determinadas por un reloj. Nuestra vida se desarrolla en un movimiento continuo. Sin embargo, cuando nos volvemos hacia lo que ha transcurrido siempre es posible distribuir ciertos fragmentos entre los puntos de división del tiempo colectivo que encontramos fuera de nosotros y que se impone desde fuera de todas las memorias individuales, precisamente porque no tiene su origen en ninguna de ellas. El tiempo social definido de esta forma será exterior a las duraciones vividas por la conciencias.

21.p.40. Los acontecimientos y las fechas que constituyen la substancia misma de la vida de un grupo no pueden ser para el individuo más que signos exteriores, frente a los que se relaciona sólo a condición de salir de sí mismo.

22. Efectivamente, si la memoria colectiva no tuviera otro material que el de las series de fechas o las listas de hechos históricos, ella no tendría más que un papel secundario en la fijación de los recuerdos. Sin embargo, esta es una concepción singularmente estrecha y que no corresponde con la realidad. Nos ha sido difícil por esta misma razón presentarla bajo esta forma. Usualmente se considera a la memoria como una facultad propiamente individual, es decir que aparece en una conciencia reducida a sus propios recursos, aislada frente a otros, y es capaz de evocar, sea a voluntad, sea por azar, los estados por los que ha transcurrido anteriormente. Dado que a pesar de todo no es posible cuestionar que ubicamos nuestros recuerdos en un espacio y en un tiempo sobre las divisiones que nos permiten relacionarnos con otros, que los ubicamos entre fechas que no tienen sentido más que en relación a los grupos de los que formamos parte, se admite que es así.

23.p.46. ¿Se puede pensar realmente en la existencia de, por un lado, una memoria sin puntos de referencia, o que sólo disponga para clasificar sus recuerdos de palabras, del lenguaje, y de algunas nociones tomadas de la vida práctica; y por otro lado de un contexto histórico colectivo, sin memoria, es decir que no fuera construido, reconstruido y conservado en las memorias individuales? No lo creemos así.

24.p.50. Es de tal modo verdad que los marcos colectivos (puntos de referencia) de la memoria no se reducen a fechas, a nombres y a fórmulas, ya que estos representan corrientes de pensamiento y de experiencia en las que sólo encontramos nuestro pasado dado que éste ha ocurrido.

25.p.52. La historia no es todo el pasado, pero tampoco es todo lo que queda del pasado. O, si se quiere, al lado de una historia viva que perpetúa o transforma a través del tiempo y en donde se encuentran estas formas de pensamiento antiguo que sólo habían desaparecido en apariencia. Si no fuera así, ¿tendríamos el derecho de hablar de memoria colectiva, y de qué nos servirían los marcos sociales que subsistirán los marcos sociales que subsistirían simplemente como nociones históricas impersonales?. 
26.p.53. Por otro lado, más allá de las imágenes y los libros presentes en la sociedad de hoy en día, el pasado ha dejado huellas algunas veces visibles y que son perceptibles en la expresión de apariencias, en el aspecto de lugares e incluso en las maneras de pensar y sentir, conservadas inconscientemente y reproducidas por ciertas personas en ciertos medios. Sin embargo, es suficiente con que dirijamos la atención a estos aspectos para reconocer que las costumbres modernas reposan sobre antiguos estratos que afloran en más de un lugar.

27.p.57. ...el recuerdo es, en buena medida, una reconstrucción del pasado con la ayuda de datos prestados del presente, y preparado además por otras reconstrucciones hechas en épocas anteriores en donde la imagen original resulta alterada. Efectivamente, si a través de la memoria nos pusiéramos en contacto directamente con tal o cual de nuestras antiguas impresiones, el recuerdo se diferenciaría -por definición- de un conjunto de ideas más o menos precisas que nuestra reflexión, auxiliada por narraciones, testimonios y confidencias de otros nos permiten recuperar eso que ha debido ser nuestro pasado. Podemos entonces llamar recuerdos a múltiples representaciones que descansan, al menos en parte, sobre testimonios y razonamientos. Es así como la parte de lo social, o si se quiere de lo histórico, en la memoria de nuestro propio pasado es bastante más amplia de lo que pensamos.

28.p.66. Para que la memoria de otros venga a reforzar y completar la nuestra, hace falta, decíamos, que los recuerdos de estos grupos de encuentren en relación con los sucesos que constituyen nuestro pasado. Cada uno de nosotros es miembro a un tiempo de múltiples grupos, de mayor o menor amplitud.

29.p.67. Si por memoria histórica se entiende la sucesión de eventos recordados por la historia nacional, no es ella, no son marcos (cadres) los que representan lo esencial de lo que llamamos memoria colectiva.

30.p.68. Cada grupo se fragmente y se cohesiona en el tiempo y en el espacio. Es al interior de estas sociedades que se desarrollan tantas memorias colectivas originales que llegan a conservar por algún tiempo el recuerdo de sucesos que únicamente guardan importancia par5a ellos, y que son más importantes mientras más pequeño es el grupo. En tanto que es fácil hacerse olvidar en una gran ciudad, los habitantes de un pueblo no dejan de observarse, y la memoria de su grupo registra fielmente todo lo que pueda conseguir de actos y gestos de cada uno de ellos, dado que así actúan y modifican a esta pequeña sociedad. En medios sociales de este tipo, los individuos piensan y recuerdan en común. Cada persona, sin duda, tiene su propia perspectiva, que sin embargo, se encuentra en correspondencia tan estrecha con la de otros que si sus recuerdos se deforman, basta con ubicarse en el punto de vista de otros para rectificarlos.

31.p.68. Si para que exista memoria es necesario que el sujeto que recuerda, individuo o grupo, tenga el sentimiento de ir a sus recuerdos desde un movimiento continuo, ¿cómo es posible que la historia sea una memoria, dado que existe una solución de continuidad entre la sociedad que lee esta historia y los grupos testigos o actores de los sucesos que relatan?

32.p.69. es verdad, uno de los objetivos de la historia puede ser precisamente tender un puente entre el pasado y el presente, y restablecer esta continuidad interrumpida. ¿Pero, cómo recrear corrientes de pensamiento colectivas que tomen su impulso del pasado cuando todo lo que permanece es el presente? 
33.p.70. La memoria colectiva se diferencia de la historia al menos sobre dos tipos de relación. Es una corriente de pensamiento continuo, de una continuidad que no tiene nada de artificial dado que retiene del pasado aquello que se encuentra vivo o capaz de vivir en la conciencia del grupo que la cultiva. Por definición ella no rebasa los límites de este grupo. Cuando un período histórico pierde interés para el período que sigue no es un mismo grupo el que olvida un fragmento de su pasado: existen en realidad dos grupos que se suceden. Los conjuntos de hombres que constituyen un mismo grupo en dos periodos sucesivos son como dos tramos que se encuentran en contacto en sus extremidades opuestas y que, sin embargo, no se unen y no forman un mismo cuerpo.

34.p.73. En realidad en el desarrollo continuo de la memoria colectiva no existen líneas de separación claramente trazadas, como en la historia, sino límites irregulares e inciertos. El presente (entendido en su extensión sobre cierta duración; la que interesa a la sociedad de hoy en día) no se opone al pasado de la manera en que se distinguen dos períodos históricos vecinos. La memoria de una sociedad se extiende tanto como puede, es decir, hasta donde alcanza la memoria de los grupos que la componen. No es por mala voluntad, antipatía, repulsión o indiferencia que la memoria colectiva olvida una gran cantidad de eventos o personajes. Sucede que los grupos que guardaban el recuerdo han desaparecido. Es difícil decir en qué momento ha desaparecido un recuerdo colectivo, y si ha salido definitivamente de la memoria de un grupo, precisamente porque es suficiente que se conserve en un parte limitada del cuerpo social para que se le pueda reencontrar.

35.p.74.Existen múltiples memorias colectivas. Es el segundo rasgo en que se diferencia de la historia. la historia es una y se puede decir que no hay más que una historia.

36.p.77. Consideremos ahora el contenido de estas memorias colectivas múltiples. No diremos que a diferencia de la historia, o si se quiere la memoria histórica, la memoria colectiva sólo retiene semejanzas. Para que se pueda hablar de memoria hace falta que las partes del período sobre las que se extienden se encuentren diferenciadas en alguna medida.. Cada uno de estos grupos posee una historia. Se distinguen personajes y eventos. Lo que llama la atención es que en la memoria las similitudes pasan a primer plano. El grupo, al momento en que mira su pasado siente que sigue siendo el mismo y toma conciencia de su identidad a través del tiempo. La historia no recupera los intervalos de tiempo en que aparentemente no pasa nada, en que la vida se limita a repetirse, bajo formas poco diversas, sin alteración esencial, sin rupturas ni sobresaltos.

37.p.77. la memoria colectiva es un mural de semejanzas, y es natural que el grupo se persuada que permanece, y además que permanece siendo el mismo; esto ocurre dado que la memoria fija su atención sobre el grupo, lo que ha cambiado son las relaciones o el contacto con otros grupos. Dado que el grupo es siempre el mismo es necesario que los cambios sean aparentes: los cambios, es decir los sucesos que se han producido en el grupo, se resuelvan en similitudes, ya que parecen tener por papel el desarrollar bajo diversos aspectos un contenido idéntico; a saber, los diversos rasgos fundamentales de un mismo grupo. 


\section{Capítulo Cuarto}

\section{La memoria Colectiva y el espacio}

\section{El grupo en su marco espacial. Poder del medio material.}

38.p.130. ... cuando cualquier suceso nos obliga a transportarnos a un nuevo medio material, antes de adaptarnos atravesamos por un período de incertidumbre, como si hubiéramos dejado atrás toda nuestra personalidad: esto es tan cierto como que las imágenes habituales del mundo exterior son inseparables de nuestro yo.

39. Todos los movimientos de un grupo pueden traducirse en términos espaciales, y en lugar ocupado por este grupo no es más que la reunión de todos los términos. Cada aspecto, cada detalle del espacio que sólo es inteligible para los miembros del grupo, porque todos los elementos del espacio que ha ocupado corresponden a diferentes aspectos de la estructura y de la vida de la sociedad, por lo menos en su dimensión más estable. Los sucesos excepcionales, en realidad, se ubican en un contexto espacial; esto ocurre porque el grupo toma conciencia de su existencia con mas intensidad y es, hasta ese momento cuando los vínculos que lo unen al lugar aparecen con mayor claridad al momento en que parecerían romperse.

40.p.134. El grupo urbano tiene la impresión de que no cambia en la medida en que el ambiente que lo rodea permanece idéntico a sí mismo.

41.p.136.Las costumbres locales resisten a las fuerzas que tienden a transformarlas, y esta resistencia permite ver mejor hasta qué punto en dichos grupos la memoria colectiva se apoya sobre imágenes espaciales.

42.p.137. Si entre las casas, las calles y los grupos de sus habitantes no existiera más que una relación accidental y de corta duración, los hombres podrían destruir sus viviendas, su barrio, su ciudad, y reconstruir en el mismo lugar una diferente, siguiendo una idea diversa: pero si las piedras se dejan transportar, no es tan fácil modificar las relaciones que se han establecido entre las piedras y los hombres. Cuando un grupo vive durante mucho tiempo en un emplazamiento adaptado a sus costumbres, no sólo sus movimientos, sino sus pensamientos son regidos por la sucesión de imágenes materiales que representan los objetos exteriores. Al transformar el medio construido las piedras y los materiales no opondrían resistencia, no así los grupos que lo habitan.

\section{Adherencia de un grupo a su espacio}

43.p.139. Para que se manifieste la resistencia de la que ya hablaba hace falta que emane de un grupo. Existen formas individuales de sentir la transformación. Un grupo, por el contrario, no se contenta con manifestar su sufrimiento. Resiste con toda la fuerza de sus tradiciones, y esta resistencia genera equilibrio en las nuevas condiciones. El grupo intenta mantenerse o transformarse en el barrio o en una calle que no son ya para él pero sobre un emplazamiento que sí le pertenece.

44.p.139. Existen viejas posadas que datan del tiempo de las diligencias y que uno visita simplemente porque se encuentran en un lugar que se desprende de la memoria colectiva de sus habitantes. Todas estas persistencias y rutinas sólo pueden explicarse por una rigidez del pensamiento en ciertos 
medios de comerciantes y clientes. Si estos grupos no se adaptan con mayor rapidez que el resto, si en múltiples circunstancias dan muestras de una extraordinaria facultad de inadaptación, es que ellos han dibujado sus límites y determinado sus reacciones en relación a una configuración dada del mundo exterior, hasta volverse parte del mismo espacio que los rodea. Para estos grupos perder su lugar en la esquina de tal calle, o a la sombra de tal muro o tal iglesia sería perder el apoyo de una tradición que los certifica como grupo, es decir, su única razón de ser.

45.p.166. Resumiendo lo que procede diremos que la mayor parte de los grupos, no solamente aquellos que resultan de la yuxtaposición permanente de sus miembros en los límites de una ciudad, una casa, o un apartamento, dibujan de alguna manera su forma en el suelo y encuentran sus recuerdos colectivos en un marco espacial definido de esta manera. En otros términos, existen tantas maneras de representarse el espacio como grupos existen.

Es posible fijar la atención sobre los límites de las propiedades, sobre los derechos que se asignan a las diferentes divisiones del suelo, distinguir los lugares ocupados por los amos y los esclavos, los nobles y la plebe, los acreedores y los deudores como zonas activas o pasivas desde donde emanan los derechos concedidos o negados a la persona. También se pueden imaginar los emplazamientos ocupados por los bienes económicos, que no adquieren un valor más que en la medida en que son ofrecidos y vendidos en tiendas y mercados, es decir en el límite que separa grupos económicos de los vendedores y sus clientes; aún aquí existe una parte del espacio que se diferencia de otros: es aquel en que reside el elemento más activo de la sociedad que se interesa por los bienes y en la que ha dejado su huella. Es posible, por último, tomar conciencia de la separación, que ocupa el primer plano en la conciencia religiosa, entre lugares sagrados y lugares profanos, ya que existen divisiones del suelo y regiones en el espacio que los grupos de fieles han elegido, y que son prohibidas a otros, en las que encuentran a la vez abrigo y apoyo para depositar sus tradiciones. Así, cada sociedad fragmenta el espacio de manera que se constituya un marco fijo en el que guarda y encuentra sus recuerdos.

Echemos marcha atrás, cerremos los ojos, remontemos el curso del tiempo tan lejos como nos sea posible hasta que detengamos nuestro pensamiento en situaciones o en personas que recordemos. Jamás salimos del espacio. No nos encontraremos en un espacio indeterminado, sino en regiones que conocemos y que sabemos localizables, porque siempre han formado parte del medio material en el que hoy nos encontramos. Tendría que esforzarme para desaparecer el entorno local, para atenerme sólo a los sentimientos que he experimentado o a las reflexiones que he realizado. Sentimientos, reflexiones, como cualquier evento deben ubicarse en un lugar en que he vivido o estado en ese momento. Intentemos ir más lejos. Cuando tocamos la época en que aún no nos representábamos, ni siquiera confusamente, los lugares, llegamos así a regiones del pasado que nuestra memoria no alcanza. Por tanto, no es exacto que para recordar tengamos que transportarnos en pensamiento fuera del espacio; por el contrario, es sólo la imagen del espacio que, en razón de su estabilidad, nos proporciona la sensación de no cambiar a través del tiempo y de encontrar el pasado en el presente: es así como podríamos definir la memoria; únicamente el espacio es lo bastante estable para poder durar sin envejecer sin perder ninguno de sus elementos.

\section{Referencia}

Halbwachs, Maurice. Fragmentos de la memoria colectiva. Athenea Digital, 2. Disponible en http://blues.uab.es/athenea/num2/Halbwachs.pdf 